\title{
International Convergence or Higher Inequality in Human Development?
}

\author{
Evidence for 1975 to 2002
}

\author{
Farhad Noorbakhsh*
}

February 2006

\begin{abstract}
The concept of convergence is extended to the human development index. Evidence of weak absolute convergence is found over 1975-2002. The results are robust and verified by various conditional $\beta$-convergence models and also supported by the evidence of weak $\sigma$-convergence. Population weighted analyses provide support for polarization in the human development index amongst developing countries but a slight reduction in world inequality. The dynamics of regional analysis reveal a movement of sub-Saharan Africa towards the low band of human development with Asia and Latin America making progress. High immobility of the early part of the period is followed by considerable upward and downward mobility in the latter part indicating a possible case of the 'twin peaks' type of polarization.
\end{abstract}

Keywords: human development, convergence, inequality, polarization JEL classification: O15, O18

Copyright @ C UNU-WIDER 2006

*Centre for Development Studies, University of Glasgow

This study is a revised version of the paper presented at the 17-18 June 2005 UNU-WIDER anniversary conference, 'WIDER Thinking Ahead: The Future of Development Economics', directed by George Mavrotas and Anthony Shorrocks.

UNU-WIDER gratefully acknowledges the financial contributions to the research programme by the governments of Denmark (Royal Ministry of Foreign Affairs), Finland (Ministry for Foreign Affairs), Norway (Royal Ministry of Foreign Affairs), Sweden (Swedish International Development Cooperation Agency_Sida) and the United Kingdom (Department for International Development). 


\section{Acknowledgements}

I am grateful to participants for their constructive comments in particular Giovanni Andrea Cornia, Mark McGillivray and Gustav Ranis. I am also grateful to Shadan Noorbakhsh for helping me with most of the computations.

The World Institute for Development Economics Research (WIDER) was established by the United Nations University (UNU) as its first research and training centre and started work in Helsinki, Finland in 1985. The Institute undertakes applied research and policy analysis on structural changes affecting the developing and transitional economies, provides a forum for the advocacy of policies leading to robust, equitable and environmentally sustainable growth, and promotes capacity strengthening and training in the field of economic and social policy making. Work is carried out by staff researchers and visiting scholars in Helsinki and through networks of collaborating scholars and institutions around the world. www.wider.unu.edu publications@wider.unu.edu

UNU World Institute for Development Economics Research (UNU-WIDER)

Katajanokanlaituri 6 B, 00160 Helsinki, Finland

Camera-ready typescript prepared by Lorraine Telfer-Taivainen at UNU-WIDER

The views expressed in this publication are those of the author(s). Publication does not imply endorsement by the Institute or the United Nations University, nor by the programme/project sponsors, of any of the views expressed. 


\section{Introduction}

This paper is about the dynamics of inequality in development between countries. The issues of inequality along with poverty are firmly back on the agenda of most international development agencies. The Millennium Development Goals (MDSs) and targets were set at the turn of the century against a background of persistent poverty in some developing countries in order to reverse the declining trends. After a few years the hopes for reversing the trends, at least in a large number of sub-Saharan African (SSA) countries, are receding significantly (Sahn and Stifel 2003). Lack of achieving a basic threshold for education and health has been regarded as a structural impediment, amongst others, to sustained economic growth and welfare in poorer countries. Despite this the levels of health, education and economic growth are declining in a number of these countries mostly in SSA. During the 1990s, some 54 countries became poorer, 34 countries experienced a drop in life expectancy and the incidence of under fivemortality rate increased in 14 countries (UNDP 2003: 34). In the table of life expectancy the bottom ten countries, mostly in SSA, have a life expectancy of below to just above 30 years, half of that of the top ten countries (WHO 2002). The most recent WHO (2003) report indicates that the increasing child mortality and decreasing life expectancy in a number of poorer countries in recent years has widened the global gap between the poor countries and the rest of the world. It seems that the large gap in life expectancy between developed and developing countries of 50 years ago has been replaced in recent years by a large gap between a group of very poor countries, mainly in SSA, and the rest of the world.

In contrast, progress in health, education and economic growth in a number of countries, mainly from South East Asia and Latin America, has been impressive. In between are countries which have made little progress, mainly from Asia and the Commonwealth of Independent States (UNDP 2003). In brief, the experience of developing countries have been mixed at best. The growth rates in particular have been a mixture of takeoffs, stagnation and decline. Between 1960-90 less developed countries had wide variability in their growth rate ranging from -2.7 to +6.9 per cent (Pritchett 1997). This begs the question of whether the world is becoming more polarized.

The research on income differences amongst countries in recent years has taken two closely related approaches: testing the hypothesis of convergence and measuring inequality and its dynamics. These are basically two sides of the same coin, both investigating whether the distribution between richer and poorer countries is moving towards equalization or more polarization. Progress in international trade and globalization has also focused the attention on international inequality. While globalization is expected to affect intra-country and inter-country inequalities there is 
little agreement on whether such effects are for better or worse. ${ }^{1}$ In general the outcome of research on world income (expenditure) inequality is controversial apparently due to the adaptation of different methodology by researchers (UNDP 2003).

A number of studies conclude that the world distribution of income has worsened over the past three to four decades. Korzeniewicz and Moran (1997) conclude that the gap between richer and poorer nations grew steadily between 1965-90 and in particular intensified during the recession years of 1980s. UNDP (1999) indicates that the ratio of income in the richer countries with 20 per cent of world population to the poorest nations with 20 per cent of world population, had risen from 30 times in 1960 to 74 times in 1977. Over a longer period the ratio of per capita income of the richest country to the poorest between 1870 and 1990 increased by almost a factor of five (Pritchett 1997). While this is the case with the very richest and very poorest countries the population-weighted measures of inequality for all countries do not seem to provide a clear picture. 2

Other studies focus on inequality between countries as well as within country inequalities by also taking into account income distribution within countries. In some cases this is done by estimating the entire distribution of income from the Gini coefficient for the country (Chotikapanich et al. 1997; Schultz 1998). More recently Sala-i-Martin (2002) concludes that between 1980-98 the world income inequality shows a decline. Dollar and Kraay (2002a, b) argue that global inequality increased significantly over the past two centuries stabilizing in 1980 and somewhat declining in more recent years. Bourguignon and Morrisson (2002) study the distribution of income amongst the world citizens by looking at the distribution amongst eleven quintiles for each country in the sample. The time span of this study is spread over two centuries concluding that in the early nineteenth century the main contributor to inequality was the differences within countries, while in more recent years the main source was the inequality between countries. Milanovic (2002) uses country household surveys for deriving the income and expenditure distribution within countries and concludes that the world income inequality during 1988-93 from a very high base. The Gini coefficient of 0.63 in 1988 increased at a rather fast pace to 0.66 in 1993.

In brief there is little agreement on whether the world inequality has declined or widened. However, the above studies, though controversial in their results, have two common features. First they agree that most of the world inequality is driven by between country inequality while the within country inequality is a low contributor to the overall inequality. Second that they all concentrate on the inequality or convergence

\footnotetext{
1 See, for example, Dollar and Kraay (2002a, b); Milanovic (2003).

2 I am grateful to the anonymous referee for indicating this ambiguity of results. Firebaugh (1999); Dowrick and Akmal (2005).
} 
of income or expenditure and use no other indicator of welfare. 3 To the best of our knowledge there is no study which extends the concept of convergence to non-income indicators. Given the spread of mass communications in recent decades it seems equally likely, if not more, that convergence amongst countries could happen with respect to the level of education and health as compared to income. This paper attempts to fill up this gap by studying international convergence of, and inequality in, development

The rest of this paper is organized as follows. Section 2 briefly discusses the approaches to the concept of convergence. Section 3 relates and tests the relevance of this concept to the human development index (HDI) and its non-income components. Section 4 tests the hypothesis of convergence for HDI. Section 5 takes into account the population concentration in deriving the measures of inequality, discusses the dynamics of change in distribution of development and the extent of upward and downward mobility. Section 6 concludes.

\section{Convergence}

According to the neoclassical growth model, given the fully competitive markets and the availability of similar technology, for the same rate of investment every economy would grow at a similar rate determined by the exogenous technical progress and population growth. Assuming a production function with constant returns to scale and the diminishing returns of capital, economies with lower levels of initial productivity enjoy a higher rate of growth in productivity and as such will catch up with the more developed economies. The more recent work on explaining the process of catching up is extensive and advocates three possible, and sometimes related, forms of convergence: $\beta$-convergence, conditional $\beta$-convergence, and $\sigma$-convergence.

$\beta$-convergence postulates that poorer countries will tend to grow faster than the richer countries. This is because of the diminishing marginal returns to capital in the richer countries, as the level of capital per labour is relatively high in these countries. Moreover, the further down a country is below its balanced growth path and the higher the lags in access to new technology the higher would be the expected growth when the country gains access to such technology (Romer 1986). In the empirical literature, running a cross-section regression of the time-averaged per capita income growth rate on the level of per capita income in the initial period tests this. A negative sign for the respective coefficient reflects the existence of convergence.

\footnotetext{
3 The only partial exception to the second point is Bourguignon and Morrison (2002) which also considers the inequality in life expectancy as a wider measure of welfare. However, this measure in their study is only employed for obtaining income over the expected life of population and not as a measure of welfare in its own right.
} 
Most of the relevant empirical literatures have attempted to test cross-country $\beta$ convergence and measure the speed of convergence. 4 The general consensus is that there exists an evidence of convergence only amongst the richer countries. There is little evidence of convergence on the part of low-income countries (Zind 1991). Some researchers go further by stating that, while the growth rates of income amongst richer countries show a historical convergence, the picture for less developed countries vis-àvis the richer countries tells a story of divergence (Pritchett 1997). Such results provide support for the idea of 'convergence clubs' in the sense that convergence may apply to groups of countries which have similar initial conditions and structures. One such club may be the richer countries and another could be developing countries or the least developed countries (LDCs). Indeed the inequality amongst such clubs may persist and may even result in further divergence. 5 The literature considers a number of possible reasons for the lack of convergence amongst poor and rich countries. One such reason is mainly related to the proposition that the nature and process of convergence requires that the institutions in the poorer countries to be supportive of inward flows of foreign capital and technology. Another explanation is based on the fact that human capital is initially higher in the richer countries resulting in a higher output and hence higher saving and investment in these countries enabling them to maintain their lead over poorer countries indefinitely. 6

The second type of convergence, conditional $\beta$-convergence, mainly takes into consideration the steady-state growth path of the country. 7 If the structural conditions of countries were different the respective long-run growth rates would be different which may result in divergence or at best a very weak convergence. This type of convergence may be tested in the same way except that the regression should also include a set of explanatory variables which would define the steady-state growth path for per capita income. 8 A negative coefficient for the per capita income in the initial period, in the presence of the extra conditional variables, suggests the existence of conditional $\beta$ convergence.

The third type, $\sigma$-convergence, envisages that the cross-country dispersion of per capita income levels across economies would tend to decrease over time implying a tendency amongst countries to equalization of per capita income in the long-run. That is, over

\footnotetext{
4 See for example Baumol (1986); Romer (1986); Baumol and Wolff (1988); Mankiw et al. (1992); Barro and Sala-i-Martin (1995); Sala-i-Martin (1996); de la Fuente (1997).

5 Martin and Sunley (1998); Quah (1993, 1996b).

6 These have been incorporated in the new endogenous growth models, which consider human capital and technology to be endogenous. Romer (1986, 1990); Sachs and Larrain (1993); Hossain (2000).
}

7 Some literature regards conditional $\beta$-convergence as a form of $\beta$-convergence and classifies it with the latter. However, the extent of empirical work on the former may warrant such typology; see for example Hossain (2000).

8 Barro (1991); Barro and Sala-i-Martin (1992). 
time the dispersion around the steady-state value decreases. $\beta$-convergence is a necessary condition for $\sigma$-convergence but not a sufficient condition (Barro and Sala-iMartin 1995).

\section{Convergence of human development index}

The concept of convergence is mainly discussed in the literature in the context of output per capita usually measured in terms of GDP per capita. This concept was developed from the Solow model and one of its main arguments relates to the diminishing returns to capital. As HDI also has none income components, it may be useful to explore the relevance of convergence to this index. For this purpose a brief description of HDI may be helpful.

The HDI is a composite index of four indicators. Its components are to reflect three major dimensions of development: longevity, knowledge and access to resources. These are to represent three of the essential choices in life 9 and are derived from the notion of human capabilities as proposed by Amartya Sen. Although this index has been criticized on a number of grounds, 10 it has been suggested that the components of the HDI together seem to provide an almost acceptable package of indicators of the level of living at an aggregate level and has been adopted frequently in recent literature.11 The dimension of longevity is directly measured by life expectancy at birth. Knowledge is presented by a measure of educational achievement based on a weighted sum of adult literacy rate and the combined first, second and third level gross enrolment ratio. Access to resources is represented by the logarithm of real per capita income (purchasing power parity).

The concept of diminishing returns would apply to the income component of HDI as discussed in the previous section. It would also seem applicable to the component of education, as the early 'units' of educational attainments are relatively easier and less costly to attain. Diminishing returns are equally applicable to the component of life expectancy as it would be much more difficult and costly to attain a higher level of life expectancy from an initially high level than a low level.

The main difference with income component is that while income in the context of diminishing returns to capital is linked to the mobility of capital, at international level for non-income components, this does not apply fully. However, the concept of diminishing returns may be linked to the point that the returns to investment in

\footnotetext{
9 UNDP (1990).

10 For some of the criticisms see McGillivray (1991); McGillivray and White (1993); Srinivasan (1994); Noorbakhsh (1998).

11 See, for example, Noorbakhsh (1999); Neumayer (2001); Kosack (2003).
} 
education and health diminish as the level of investment in health and education increases. Two indicators of adult literacy and combined enrolment ratios measure the dimension of education in HDI. The returns to investment in education, for improving adult literacy and increasing the combined enrolment ratio, will be higher in countries that are relatively at a lower level of initial education as measured by these indicators. Similarly the returns to investment in health, for improving life expectancy, will be higher in countries which have a lower life expectancy as compared to those with a higher level of life expectancy. In brief, countries with lower levels of education and health will grow faster over time, in terms of education and health, than countries which initially enjoy higher levels.

More specifically in a country which has reached a very high level of primary and secondary enrolment, only the relatively more expensive investment in tertiary education could improve the level of educational attainment used in HDI. Similarly for an equal amount of investment in health facilities in two countries with similar conditions but with low and high levels of life expectancy, relatively more life expectancy could be gained in the country with the low initial level of life expectancy.

In the light of the discussion above, the fact that the literacy and enrolment ratio components of HDI are both defined across countries regardless of differences in quality and the existence of an upper limit for these indicators, it seems plausible to suggest that the concept of convergence would be equally, if not more, applicable to education and life expectancy. Similarly it may be argued that access to technology relevant to education and health for improving the level of adult literacy, combined enrolment and life expectancy in countries which are at a lower level of these indicators is relatively more plausible as compared to access to technology required for obtaining a higher level of production in the standard neoclassical model.

We tested these suggestions empirically by estimating the parameters of the following equation, which is mainly the growth regression equation 12 for adult literacy and life expectancy:

$\left(\frac{1}{T}\right) \log \left(\frac{x_{i t+T}}{x_{i t}}\right)=\alpha+\beta \log \left(x_{i t}\right)+u_{i t}$

where $x_{i t}=\frac{x_{i t}}{\overline{x_{t}}}$ is the ratio of $x$ (adult literacy or life expectancy) in the $i^{\text {th }}$ country to the average for the sample of countries under consideration. $\left(\frac{1}{T}\right) \log \left(\frac{x_{i t+T}}{x_{i t}}\right)$ is the annualized growth of the variable $x$ in the $i^{\text {th }}$ country over the period of $t$ and $t+T$. A negative value of $\beta$ would be an evidence of $\beta$-convergence. Table 1 shows the results for the

12 For examples of the use of this type of regression see the literature referred to in Section 2. 
annualized adult literacy growth (1975-98) and life expectancy (1977-98) for a sample of 93 developing countries.

Table 1: Convergence results for adult literacy and life expectancy

\begin{tabular}{lcc}
\hline Indicators & Adult literacy & Life expectancy \\
\hline Constant & 0.001 & -0.000 \\
& $(3.15)^{\star \star \star}$ & $(-0.23)$ \\
Log $x_{t}$ & -0.020 & -0.009 \\
N & $(-25.44)^{\star \star \star}$ & $(-3.00)^{\star \star \star}$ \\
Adjusted R & $92^{2}$ & 92 \\
F statistic & $0.88^{\star \star \star}$ & 0.08 \\
\hline
\end{tabular}

Note: ${ }^{* \star}$ Significant at the $1 \%$ level. Figures in brackets are t-ratios.

Source: Author.

The results in Table 1 provide support for the suggestion that the diminishing returns to investment in education and health are indeed the case in developing countries. The $\beta$ coefficient for both indicators is negative and highly significant indicating that countries with a lower initial level of adult literacy (life expectancy) grow faster in terms of these indicators. Briefly we may conclude that it is plausible to extend the concept of diminishing returns to investment to the non-income components of HDI. Consequently it would be possible that countries with a low level of development in the initial period would have a higher rate of growth in HDI in the long-run than those with high level development in the initial period.

We test for the existence of $\beta$-convergence in HDI by employing the following $\mathrm{K}$ models:

$\left(\frac{1}{T}\right) \log \left(\frac{h d i_{i t+T}}{h d i_{i t}}\right)=\alpha+\beta \log \left(h d i_{i t}\right)+\sum_{j=1}^{J_{k}} \lambda_{i j} S_{i j}+u_{i t} \quad$ for $\mathrm{k}=0,1,2, \ldots, \mathrm{K}$

where $h d i_{i t}=\frac{H D I_{i t}}{\overline{H D I_{t}}}$ is the ratio of HDI in the $i^{\text {th }}$ country to the average for the sample of countries under consideration. $\left(\frac{1}{T}\right) \log \left(\frac{h d i_{i t+T}}{h d i_{i t}}\right)$ is the annualized growth of the variable HDI in the $i^{\text {th }}$ country over the period of $t$ and $t+T$. A value of $\beta$ in the range of $-1<\beta<0$ would be an evidence of $\beta$-convergence. That is, the nearer the value of $\beta$ to -1 , the higher the speed of convergence and the nearer to zero the lower the speed of convergence. By implication zero means no convergence and a positive value for $\beta$ indicates a divergence. $S_{i j}$ is the $j^{\text {th }}$ structural condition variable and $\lambda_{i j}$ is the respective parameter to be estimated. There are K different models where the structural conditional variables change and for $\mathrm{k}=0$ all $S_{i j}$ are zeros, i.e. the absolute convergence model. 
The data for HDI for the period of 1975 to 2002 (at intervals of five years up to 2000 and two years for the last period) has been taken from UNDP (2004). As for some countries time series start at the middle of this period; adjustment in the length of the period in equation (2) are made to reflect this for the respective countries.

The variables included for reflecting conditional convergence are selected on the grounds of contributing to the components of HDI. There are two types of variables which may take account of the external and domestic contributions to HDI. In the conditional beta-convergence model it is postulated that the institutions in poorer countries should be supportive of inward flows of foreign capital and technology. While a certain amount of technology is transferred with foreign direct investment, the openness of the country to international trade also may be responsible for such a transfer. We have selected both these variables: foreign direct investment as a percentage of GDP (FDI) and trade as a percentage of GDP (TRD). Foreign aid as a percentage of GDP (AID) has also been included as a substantial amount of aid is geared to improving the health and educational status of the recipient country. These variables reflect the external sources of contribution to HDI.

We have selected three variables to reflect the domestic contributions to HDI: gross domestic investment as a percentage of GDP (GDI), the average annual growth rate of public sector expenditure on education and health as a percentage of GDP (gPEEH) and the number of telephone lines per population (TEL) to reflect the level of infrastructure.13 Our initial sample of 93 countries includes 61 medium and 32 low human development countries. We have not included the high human development countries in the $\beta$-convergence models on the grounds of the general consensus, in the literature of growth, on the possible existence of wide apart convergence clubs for rich and developing countries. In addition the variables selected to represent the structural conditions would be widely different for the high human development countries. 14

\section{Empirical results for convergence hypotheses}

We tested the hypothesis of $\beta$-convergence, in its absolute and conditional forms, through a number of models for different samples. Table 2 shows the results for the sample of medium and low human development countries.

\footnotetext{
13 The data for FDI, AID, GDI and TRD are the totals over 1973-98, for gPEEH average annual for 1990-98 and TEL for 1990. The source for all is the World Development Indicators STAR disk.

14 For example AID or TEL may be inappropriate variables for the high human development group of countries.
} 
Table 2: $\beta$-convergence models of HDI for medium and low development countries

\begin{tabular}{lcrr}
\hline Models/variables & 1 & 2 & 3 \\
\hline Constant & $-0.0004{ }^{* *}$ & 0.0000 & 0.0003 \\
& $(-2.01)^{*}$ & $(0.00)$ & $(0.08)$ \\
Log di $_{t}$ & -0.0081 & -0.0115 & -0.0112 \\
& $(-5.03)^{* * *}$ & $(-3.74)^{* * *}$ & $(-3.71)^{* * *}$ \\
Log GDI & & 0.0033 & 0.0036 \\
& & $(1.98)^{* *}$ & $(2.17)^{* *}$ \\
gPEEH & & 0.0000 & 0.0000 \\
& & $(1.34)$ & $(1.28)$ \\
Log TEL & & 0.0003 & 0.0005 \\
& & $(0.48)$ & $(0.80)$ \\
Log AID & & -0.0003 & \\
& & $(-0.61)$ & 0.0004 \\
Log FDI & & 0.0004 & $(0.78)$ \\
& & $(0.76)$ & -0.0035 \\
Log TRD & & -0.0030 & $(-2.86)^{* * *}$ \\
N & & $(-1.97)^{* *}$ & 75 \\
Adjusted R & & 75 & 0.32 \\
F statistics & 93 & 0.31 & 6.80 \\
\hline
\end{tabular}

Note: ${ }^{\star * \star}$ Significant at the $1 \%$ level; ${ }^{*}$ Significant at the $5 \%$ level. Figures in parenthesis are t-ratios.

Source: Author.

Model 1 reflects the absolute convergence hypothesis. The negative sign of $h d i_{t}$ is as expected and it is significant at the 1 per cent level indicating a clear tendency to convergence amongst the countries in the sample. However, the magnitude of the coefficient is very low reflecting a very slow speed of convergence over the period.

Model 2 introduces the conditional $\beta$-convergence. The conditions employed are of external and internal origins. Theoretically, convergence is conditional on governments being supportive of foreign capital transfer and technology. Often the literature argues that the transfer of technology and capital is through foreign direct investment, openness and sometimes aid. These variables are normally regarded as reflecting the degree of globalization in a country. Other variables are more directly of domestic origin. The gross domestic investment as a percentage of GDP is relevant to the income component of HDI, while the growth of public sector expenditure on education and health as a percentage of GDP are directly relevant to the education and longevity components of HDI. The variable reflecting the number of telephone lines per population is included as a proxy for domestic infrastructure.

In the presence of these variables in Model 2 the coefficient of $h d i_{t}$ has remained negative and highly significant. GDI has a positive coefficient significant at the 5 per cent level indicating that the growth differential in HDI is a positive function of investment, which most probably works through the income component of the index. 
The growth rate of public sector expenditure on education and health expectedly has a positive sign but not significant. Other variables are insignificant except trade, which is significant with a negative sign. Overall Model 2 provides support for the proposition of conditional convergence in the sample over the period. However, the speed of convergence is low.

Table 3: $\beta$-convergence models of HDI for medium human development countries

\begin{tabular}{lccc}
\hline Models/variables & 1 & 2 & 3 \\
\hline Constant & 0.0007 & -0.0027 & -0.0025 \\
& $(2.83)^{* * *}$ & $(-0.85)$ & $(-0.82)$ \\
Log $h d i_{t}$ & -0.0170 & $-0.0161^{* * *}$ & $-0.0159^{* * *}$ \\
& $(-7.42)^{* * *}$ & $(-5.06)$ & $(-5.21)$ \\
Log GDI & & $0.0031^{* *}$ & $0.0032^{* *}$ \\
& & $(2.23)$ & $(2.38)$ \\
gPEEH & & 0.0000 & 0.0000 \\
& & $(0.41)$ & $(0.37)$ \\
Log TEL & & -0.0002 & -0.0001 \\
& & $-0.33)$ & $(-0.24)$ \\
Log AID & & -0.0001 & \\
& & $(-0.31)$ & 0.0002 \\
Log FDI & & 0.0002 & $(0.35)$ \\
& & $(0.37)$ & -0.0016 \\
Log TRD & & -0.0014 & $(-1.73)$ \\
& & $(-1.13)$ & 51 \\
$N$ & 61 & 51 & 0.63 \\
Adjusted R & & 0.62 & $14.97^{* * *}$ \\
F statistics & 0.47 & 12.58 & \\
\hline
\end{tabular}

Note: ${ }^{*}$ Significant at the $1 \%$ level. ${ }^{*}$ Significant at the $5 \%$ level. Figures in parenthesis are t-ratios.

Source: Author.

In Model 3 AID is excluded from the equation on the basis of a possible argument that aid may have been more provided to countries which have had a lower level of development, hence the question of endogeniety may arise. The results do not change and the coefficient of $h d i_{t}$ remains negative and highly significant. Overall the results are robust indicating strongly that there has been a conditional convergence in HDI close to absolute convergence though in all cases the speed of convergence has been slow.

A fundamental idea behind the concept of absolute convergence is that the structural conditions in countries are similar. The literature of growth argues that there may be clubs of convergence where the members of such specific clubs have a tendency to converge. With this in mind we split the sample into medium development and low development countries to see if the results would be different. Table 3 provides the results for the same models for medium development countries. 
The most interesting feature is that the same picture for absolute and conditional convergence emerges, as the coefficient of $h d i_{t}$ remains negative and highly significant in all models. The magnitude of this coefficient once again reveals a slow speed of convergence but higher than that of the full sample. In this respect the results are very robust. The globalization variables of AID, FDI and TRD are not significant in the last two models. Overall these models for the medium HDI sample seems to provide sensible results with a rather high adjusted $\mathrm{R}^{2}$ of up to 0.63 and highly significant F-statistics.

Table 4: $\beta$-convergence models of HDI for low human development countries

\begin{tabular}{|c|c|c|c|}
\hline Models/variables & 1 & 2 & 3 \\
\hline \multirow[t]{2}{*}{ Constant } & -0.0032 & 0.0083 & 0.0076 \\
\hline & $(-4.68)^{* \star *}$ & (1.06) & $(0.93)$ \\
\hline \multirow[t]{2}{*}{$\log h d i_{t}$} & -0.0192 & -0.0221 & -0.0222 \\
\hline & $(-4.97)^{\star \star \star}$ & $(-3.72)^{\star \star \star}$ & $(-3.59)^{* \star \star}$ \\
\hline \multirow[t]{2}{*}{ Log GDI } & & -0.0001 & -0.0009 \\
\hline & & $(-0.28)$ & $(-0.24)$ \\
\hline \multirow[t]{2}{*}{ gPEEH } & & 0.0001 & 0.0001 \\
\hline & & $(1.47)$ & $(1.55)$ \\
\hline \multirow[t]{2}{*}{ Log TEL } & & 0.0019 & 0.0025 \\
\hline & & $(1.00)$ & $(1.28)$ \\
\hline \multirow[t]{2}{*}{ Log AID } & & -0.0020 & \\
\hline & & $(-1.57)$ & \\
\hline \multirow[t]{2}{*}{ Log FDI } & & 0.0001 & 0.0017 \\
\hline & & $(0.65)$ & $(1.21)$ \\
\hline \multirow[t]{2}{*}{ Log TRD } & & -0.0022 & -0.0039 \\
\hline & & $(-0.69)$ & $(-1.30)$ \\
\hline $\mathrm{N}$ & 32 & 24 & 24 \\
\hline Adjusted $\mathrm{R}^{2}$ & 0.43 & 0.46 & 0.41 \\
\hline F statistics & $24.67^{\star \star \star}$ & $3.72^{\star \star \star}$ & $3.62^{\star *}$ \\
\hline
\end{tabular}

Note: ${ }^{* *}$ Significant at the $1 \%$ level. ${ }^{*}$ Significant at the $5 \%$ level. Figures in parenthesis are t-ratios.

Source: Author.

Table 4 shows the results for the same models of absolute and conditional $\beta$-convergence for low development countries. Once again the models are very robust as the coefficient of $h d i_{t}$ remains negative and highly significant in all models. The magnitude of this coefficient is nearly one third higher than that of the medium HDI sample though still indicating a slow speed of convergence.

The last type of convergence, $\sigma$-convergence, hypothesizes that the deviations from the long-run cross-country mean have a tendency to converge towards the mean over time. 15 The underlying assumption for this type of convergence is that the steady-state value of the variable concerned and its time trends are the same for all countries as the

15 Barro (1991); Barro and Sala-i-Martin (1992). 
constant term in equation (2) conceptually includes the steady-state value of the HDI variable (Barro and Sala-i-Martin 1995). In the empirical literature the standard deviation of the logarithm of the variable concerned is commonly used for investigating if this type of convergence has taken place.

Table 5: Measures of $\sigma$-convergence for HDI

\begin{tabular}{llll}
\hline Year & SD $\log \left(h d i_{i t}\right)$ & CV & GiniC \\
\hline 1975 & 0.1371 & 0.2941 & 0.1674 \\
1980 & 0.1330 & 0.2792 & 0.1602 \\
1985 & 0.1300 & 0.2698 & 0.1542 \\
1990 & 0.1269 & 0.2643 & 0.1507 \\
1995 & 0.1243 & 0.2588 & 0.1465 \\
2002 & 0.1215 & 0.2554 & 0.1439 \\
\hline
\end{tabular}

Source: Author.

Table 5 shows the results for three different measures of dispersion of HDI amongst countries over time. The first column presents the standard deviation of $\log (h d i)$. The second column depicts the results for the coefficient of variation (CV) which is the ratio of the standard deviation to the mean of distribution. The last column shows the Gini coefficient (GiniC) as a measure of dispersion amongst countries. 16 All measures show a convergence amongst middle and low development countries. However, considering the length of the period, the pace of convergence seems to be very slow confirming our previous results for $\beta$-convergence.

\section{Population-weighted measures of inequality and dynamics of mobility}

The measures considered so far were for investigating the possible occurrence of convergence as this particular strand of literature on inequality and convergence postulates. However, these measures assess the degree of concentration between countries without taking into account the population of the countries concerned. Furthermore as convergence is basically about poor countries catching up with rich countries, it is argued that, it should be more relevant to the cross sectional of the distribution of the phenomena under consideration and not to the convergence of individual economies to their own individual steady state (Quah 1996a). This is to do with the dynamics of mobility in distribution.

To start with we have employed two measures of inequality, which take into account the population share of each country, for investigating the extent and dynamics of inequality amongst countries. These measures are the Gini coefficient and the Theil

\footnotetext{
16 The GiniC coefficient has been computed without taking the size of the population into account. It is a measure of the concentration (dispersion) of indicator HDI amongst countries regardless of their population size. See Pyatt et al. (1980); Milanovic (1997); Noorbakhsh (2003).
} 
index.17 As the concept of inequality is not constrained by the argument of clubs of convergence it would be interesting to asses both these measures for two separate samples: the medium and low development sample (ML) and for all countries including the high development countries. Furthermore we limit our study to measuring betweencountry inequalities as most recent literature, which have used the decomposed measures for including the within country sources of inequality as well, conclude that the main source of inequality is the between-country component. 18 Table 6 shows the results for our two samples.

Table 6: Population weighted measures of inequality

\begin{tabular}{lllll}
\hline Time & GiniP ML & Theil index ML & $\begin{array}{l}\text { GiniP all } \\
\text { countries }\end{array}$ & $\begin{array}{l}\text { Theil index } \\
\text { all countries }\end{array}$ \\
\hline 1975 & 0.1001 & 0.6962 & 0.1887 & 0.6708 \\
1980 & 0.1198 & 0.7355 & 0.1878 & 0.7059 \\
1985 & 0.1220 & 0.7285 & 0.1805 & 0.7008 \\
1990 & 0.1235 & 0.6827 & 0.1745 & 0.6594 \\
1995 & 0.1220 & 0.6781 & 0.1678 & 0.6616 \\
2002 & 0.1232 & 0.6654 & 0.1644 & 0.6588 \\
\hline
\end{tabular}

Source: Author.

For the ML development sample the Gini coefficient has increased from 1975 to 1990 with a drop in 1995 before resuming its upward trend. This indeed is showing a picture of divergence amongst ML development countries. Theil index for these countries shows an initial increase before coming down; its decline over the entire period is hardly considerable. This is in line with the results of weak convergence in the previous section. As for the full sample Gini shows a steady but relatively weak decline over 28 years while the Thiel index depicts an initial increase before coming down in 2002 to just below its level in 1975. The overall picture for both samples does not show a considerable decrease in equality in development amongst countries.

17 For Gini coefficient:

$\operatorname{Gini}=\frac{1}{\mu} \sum_{i=1}^{N} \sum_{j=1}^{N} f\left(y_{i}\right) f\left(y_{j}\right)\left|y_{i}-y_{j}\right|$

where for $N$ countries $y_{i}$ is the value of HDI in country $i, f\left(y_{i}\right)$ is the population share of country $i$ in total population and $\mu$ is the mean value for HDI. For Theil index :

$T=\sum_{i=1}^{N} Y_{i} \log \frac{Y_{i}}{X_{i}}$

where $Y_{i}$ and $X_{i}$ are the HDI and population shares of country $i$ respectively.

18 Furthermore there is a controversy in the procedure used for finding the within country distribution and hence the within country inequality for income. In addition the extension of such procedures for deriving the within country distribution of the non-income components of HDI may be even more controversial. Lastly because education and health are more public goods in most developing countries it is more likely that their distributions within countries are, relatively speaking, more even than that of income. Schultz (1998); Milanovic (2002); Bourguignon and Morrison (2002). 
Table 7: Dynamics of regional composition of HDI for selected quintiles (\%)

\begin{tabular}{|c|c|c|c|c|c|c|c|c|}
\hline \multirow[t]{2}{*}{ World } & \multirow[t]{2}{*}{ Quintiles } & \multicolumn{4}{|c|}{ Japan, } & \multirow[b]{2}{*}{ Eastern } & \multirow[b]{2}{*}{$\begin{array}{l}\text { Europe and } \\
\text { its offshoots }\end{array}$} & \multirow[b]{2}{*}{ Total } \\
\hline & & Africa & $\begin{array}{r}\text { Asia and } \\
\text { Pacific }\end{array}$ & $\begin{array}{l}\text { Hong Kong } \\
\text { and Korea }\end{array}$ & Latin America & & & \\
\hline \multirow[t]{4}{*}{1975} & Total & 33.0 & 18.0 & 3.0 & 21.0 & 1.0 & 24.0 & 100 \\
\hline & bottom 20\% & 85.0 & 15.0 & 0.0 & 0.0 & 0.0 & 0.0 & 100 \\
\hline & middle $60 \%$ & 26.7 & 25.0 & 3.3 & 35.0 & 1.7 & 8.3 & 100 \\
\hline & top $20 \%$ & 0.0 & 0.0 & 5.0 & 0.0 & 0.0 & 95.0 & 100 \\
\hline \multirow[t]{4}{*}{1980} & Total & 30.1 & 18.6 & 2.7 & 20.4 & 6.2 & 22.1 & 100 \\
\hline & bottom $20 \%$ & 82.6 & 17.4 & 0.0 & 0.0 & 0.0 & 0.0 & 100 \\
\hline & middle $60 \%$ & 22.4 & 25.4 & 3.0 & 32.8 & 10.4 & 6.0 & 100 \\
\hline & top $20 \%$ & 0.0 & 0.0 & 4.3 & 4.3 & 0.0 & 91.3 & 100 \\
\hline \multirow[t]{4}{*}{1985} & Total & 32.8 & 19.7 & 2.5 & 18.9 & 5.7 & 20.5 & 100 \\
\hline & bottom $20 \%$ & 88.0 & 12.0 & 0.0 & 0.0 & 0.0 & 0.0 & 100 \\
\hline & middle $60 \%$ & 25.0 & 29.2 & 1.4 & 30.6 & 9.7 & 4.2 & 100 \\
\hline & top $20 \%$ & 0.0 & 0.0 & 8.0 & 4.0 & 0.0 & 88.0 & 100 \\
\hline \multirow[t]{4}{*}{1990} & Total & 28.7 & 22.8 & 2.2 & 16.2 & 11.8 & 18.4 & 100 \\
\hline & bottom $20 \%$ & 77.8 & 22.2 & 0.0 & 0.0 & 0.0 & 0.0 & 100 \\
\hline & middle $60 \%$ & 22.0 & 30.5 & 1.2 & 25.6 & 19.5 & 1.2 & 100 \\
\hline & top $20 \%$ & 0.0 & 0.0 & 7.4 & 3.7 & 0.0 & 88.9 & 100 \\
\hline \multirow[t]{4}{*}{1995} & Total & 30.0 & 22.9 & 2.1 & 15.7 & 11.4 & 17.9 & 100 \\
\hline & bottom $20 \%$ & 85.7 & 14.3 & 0.0 & 0.0 & 0.0 & 0.0 & 100 \\
\hline & middle $60 \%$ & 21.4 & 32.1 & 1.2 & 25.0 & 19.0 & 1.2 & 100 \\
\hline & top $20 \%$ & 0.0 & 3.6 & 7.1 & 3.6 & 0.0 & 85.7 & 100 \\
\hline \multirow[t]{4}{*}{2002} & Total & 30.0 & 22.9 & 2.1 & 15.7 & 11.4 & 17.9 & 100 \\
\hline & bottom $20 \%$ & 92.8 & 7.2 & 0.0 & 0.0 & 0.0 & 0.0 & 100 \\
\hline & middle $60 \%$ & 18.2 & 33.5 & 1.2 & 25.9 & 20.0 & 1.2 & 100 \\
\hline & top $20 \%$ & 0.0 & 3.4 & 7.1 & 3.7 & 0.0 & 85.8 & 100 \\
\hline
\end{tabular}

Source: Author.

Another way of looking at the international distribution of HDI is to focus on the degree of mobility of various regions in the world over time. Table 7 shows the regional composition of various quintiles of the international distribution of HDI for the period of our sample for all countries. For 1975 the first row of Table 7 shows the distribution of countries in various regions of the world. 85 per cent of countries in the bottom 20 per cent of HDI value were in Africa with Asia and Pacific accounting for 15 per cent. The top 20 per cent band is exclusive to European countries and their offshoots (95 per cent) and Japan. Latin American countries dominate the middle 60 per cent band with relatively lesser presence from other regions. There is very little change in the bottom 20 per cent band in 1980 which is again dominated primarily by African and to a lesser extent by Asian countries. This is coupled with relatively little change in the middle 
band composition. As for the top band the dominance of Europe and its offshoots is not challenged but a relatively small presence of Latin American countries in this band is notable. 1985 shows a worsening of the position of African countries and an improvement in the case of Asian countries in the bottom 20 per cent band with little notable change in other bands. Fewer African and more Asian countries appear in the bottom 20 per cent band in 1990 before the worsening trend for Africa resumes to its path in 1995 and 2002. For the last two periods the share of African (Asian) countries in the lower band has increased (decreased) notably. The entry of some Asian countries into the top 20 per cent band is interesting. However, despite the presence of countries from all regions (except Africa) in the top band in 2002, the European countries and their offshoots dominate this band.

The overall picture for the dynamics of human development over the period of 1975 to 2002 reveals little upward mobility for the poor countries of the world. The relative situation for SSA countries worsened, for some Asian countries it improved, with the top band being dominated by European countries and their offshoots.

A complementary way of reviewing the dynamics of human development disparities is to find out how countries change position over time. This approach, adopted in recent literature investigates the degree of mobility of countries (with the size of their population taken into account) moving from one band of HDI to another over time.19 Table 8 shows the results for four HDI bands relative to the mean of the sample and for various sub-periods.

For each period interval the percentage population in HDI bands in the initial year which have moved to various bands in the final year are shown. The bands are selected such that they are spread around the mean evenly. The row entitled 'total population share' shows the percentage of population in each band at the beginning of the period and the column with the same title shows the same at the end of the period. A comparison of this row and column reveals the change in inequality over the relevant period. The details of such mobility are shown in the transition matrix (figures in italics). The immobility ratio is computed as the percentage of population not changing band by the final year (the diagonal of the transition matrix). The upward and downward mobility are the shares of population moving to upper or lower bands (the upper and lower off diagonal elements of the transition matrix respectively).

There is little evidence of change in distribution for the period of 1975-80. More than 98 per cent of population remained in the same bands as the initial year. There is a little more downward mobility for the period of 1980-85, though essentially there is a high degree of immobility for this period. The degree of immobility for 1985-90 is very high

19 See Quah (1996a) and Bourguignon and Morrisson (2002) for its application to income. 
Table 8. Relative populated HDI mobility matrix and mobility ratios (\%)

\begin{tabular}{|c|c|c|c|c|c|c|}
\hline $\begin{array}{l}\text { HDI in final year relative to } \\
\text { mean }\end{array}$ & $\begin{array}{l}\text { More than } \\
4 / 3 \text { mean }\end{array}$ & $\begin{array}{l}1 \text { to } 4 / 3 \\
\text { mean }\end{array}$ & $\begin{array}{l}2 / 3 \text { to } 1 \\
\text { mean }\end{array}$ & $\begin{array}{l}\text { Less than } \\
2 / 3 \text { mean }\end{array}$ & $\begin{array}{l}\text { Total } \\
\text { population } \\
\text { share }\end{array}$ & $\begin{array}{l}\text { Mobility } \\
\text { ratio }\end{array}$ \\
\hline \multicolumn{7}{|l|}{$1975-80$} \\
\hline More than 4/3 mean & 99.6 & 0.0 & 0.0 & 0.0 & 19.9 & \\
\hline 1 to $4 / 3$ mean & 0.4 & 100.0 & 0.0 & 0.0 & 17.7 & \\
\hline $2 / 3$ to 1 mean & 0.0 & 0.0 & 99.6 & 5.5 & 53.8 & \\
\hline Less than $2 / 3$ mean & 0.0 & 0.0 & 0.4 & 94.5 & 8.6 & \\
\hline Total population share & 20.0 & 17.7 & 53.4 & 8.9 & 100.0 & \\
\hline Immobility ratio & & & & & & 98.4 \\
\hline Upward mobility & & & & & & 1.4 \\
\hline Downward mobility & & & & & & 0.2 \\
\hline \multicolumn{7}{|l|}{$1980-85$} \\
\hline More than 4/3 mean & 76.9 & 0.0 & 0.0 & 0.0 & 14.5 & \\
\hline 1 to $4 / 3$ mean & 23.1 & 100.0 & 0.0 & 0.0 & 22.7 & \\
\hline $2 / 3$ to 1 mean & 0.0 & 0.0 & 98.3 & 0.0 & 53.1 & \\
\hline Less than $2 / 3$ mean & 0.0 & 0.0 & 1.7 & 100.0 & 9.7 & \\
\hline Total population share & 18.9 & 18.3 & 54.0 & 8.8 & 100.0 & \\
\hline Immobility ratio & & & & & & 93.8 \\
\hline Upward mobility & & & & & & 0.0 \\
\hline Downward mobility & & & & & & 6.2 \\
\hline \multicolumn{7}{|l|}{$1985-90$} \\
\hline More than $4 / 3$ mean & 95.0 & 0.0 & 0.0 & 0.0 & 11.3 & \\
\hline 1 to $4 / 3$ mean & 5.0 & 100.0 & 2.2 & 0.0 & 26.0 & \\
\hline $2 / 3$ to 1 mean & 0.0 & 0.0 & 97.8 & 0.0 & 52.4 & \\
\hline Less than $2 / 3$ mean & 0.0 & 0.0 & 0.0 & 100.0 & 10.3 & \\
\hline Total population share & 11.9 & 24.2 & 53.6 & 10.3 & 100.0 & \\
\hline Immobility ratio & & & & & & 98.2 \\
\hline Upward mobility & & & & & & 0.5 \\
\hline Downward mobility & & & & & & 1.3 \\
\hline \multicolumn{7}{|l|}{$1990-95$} \\
\hline More than $4 / 3$ mean & 85.4 & 7.1 & 0.0 & 0.0 & 11.0 & \\
\hline 1 to $4 / 3$ mean & 14.6 & 92.8 & 2.8 & 0.0 & 26.8 & \\
\hline $2 / 3$ to 1 mean & 0.0 & 0.1 & 96.6 & 26.3 & 53.9 & \\
\hline Less than $2 / 3$ mean & 0.0 & 0.0 & 0.6 & 73.7 & 8.3 & \\
\hline Total population share & 10.8 & 25.6 & 52.8 & 10.8 & 100.0 & \\
\hline Immobility ratio & & & & & & 87.1 \\
\hline Upward mobility & & & & & & 9.1 \\
\hline Downward mobility & & & & & & 3.8 \\
\hline \multicolumn{7}{|l|}{$1995-2002$} \\
\hline More than $4 / 3$ mean & 100.0 & 8.0 & 0.0 & 0.0 & 12.7 & \\
\hline 1 to $4 / 3$ mean & 0.0 & 88.6 & 43.3 & 0.0 & 47.6 & \\
\hline $2 / 3$ to 1 mean & 0.0 & 3.4 & 56.7 & 33.5 & 33.9 & \\
\hline Less than $2 / 3$ mean & 0.0 & 0.0 & 0.0 & 66.5 & 5.8 & \\
\hline Total population share & 10.6 & 26.5 & 54.3 & 8.6 & 100.0 & \\
\hline Immobility ratio & & & & & & 77.9 \\
\hline Upward mobility & & & & & & 21.2 \\
\hline Downward mobility & & & & & & 0.9 \\
\hline
\end{tabular}


1975-2002

\begin{tabular}{|c|c|c|c|c|c|c|}
\hline More than $4 / 3$ mean & 66.6 & 0.0 & 0.0 & 0.0 & 13.4 & \\
\hline 1 to $4 / 3$ mean & 33.4 & 95.3 & 51.9 & 0.0 & 52.5 & \\
\hline $2 / 3$ to 1 mean & 0.0 & 4.7 & 46.3 & 54.8 & 29.0 & \\
\hline Less than $2 / 3$ mean & 0.0 & 0.0 & 1.8 & 45.2 & 5.1 & \\
\hline Total population share & 20.0 & 17.7 & 53.4 & 8.9 & 100.0 & \\
\hline Immobility ratio & & & & & & 63.3 \\
\hline Upward mobility & & & & & & 26.7 \\
\hline Downward mobility & & & & & & 10.0 \\
\hline
\end{tabular}

Source: Author.

again. It is during the period of 1990-95 that some upward mobility takes place. This is mainly due to some populated countries moving to a higher band (amongst them Pakistan, Iran, Sudan and Tunis). The downward mobility for this period is mainly due to some European countries or their offshoots dropping out of the top band due to this band not being wide enough to accommodate them all. The relatively big move takes place for the period of 1995-2002. During this period more than 21 per cent of population moved upwards. Almost all this transition is in the middle part of the distribution and is explained by the upward movement of two highly populated countries: China and Bangladesh. The change in distribution is evident in the transition matrix as well as the changes in the overall distribution at the final period as compared to the initial period (column and row of 'total population share'). For this period, and to some extent for the previous two periods, we see a movement towards the 'twin peaks' in distribution as suggested by Quah (1996a) and observed for income data in the long run by Jones (1997) and Bourguignon and Morrisson (2002).

The final section of Table 8 shows the mobility for the entire period of our sample, 1975-2002. The twin peak effect is clearer in this longer interval. There are clear upward and downward movements in development over the period of 28 years. The upward mobility has resulted in more than 26 per cent of population in the sample to move from the bottom two bands to the upper middle bands. There is a nearly 55 per cent movement from the bottom band to the next band coupled by nearly 52 per cent movement from the $2 / 3$ to 1 mean band to the next upper band. The downward movement is mostly due to some European countries and their offshoots dropping to a lower band coupled with some relatively small downward movement from the second top band to the third. The overall changes in the distribution of development in 2002 as compared to 1975 (column and row of 'total population share') depict a clear picture of movement from the bottom to the lower-middle band, from the lower-middle to the upper-middle band and also from the top band towards the middle-upper band. The mobility ratios indicate that nearly 27 per cent of population moved upward as compared to a downward mobility of 10 per cent and an immobility ratio of just above 63 per cent during this period. 


\section{Conclusion and policy implications}

The concepts of convergence and inequality could be usefully employed in studying the evolvement of development over time. The extension of conversion hypothesis to the non-income components of HDI could be validated conceptually and empirically. The growth regression for the medium and low development countries shows an evidence of weak absolute convergence in development over 28 years. These findings are robust and remain the same for various models of conditional convergence. The same is established for sub-samples of medium and also low development countries. The measures of $\sigma$ convergence are in line with those for weak $\beta$-convergence. When the population size of countries are taken into account the results differ. The Gini coefficient for medium and low development countries shows a worsening of inequality while in the case of all countries sample we see little change in inequality over the 28 years time span of this study. A regional breakdown of the sample over time clearly showed that in 2002 almost all countries in the bottom 20 per cent of HDI are SSA countries-a situation worse than that of 1975. During the 1975 to 2002 period, the Asian and Latin American countries experienced considerable progress in human development.

Regarding population mobility between mean-relative HDI bands there is little movement for the first three five-year periods from 1975 to 1990. It is during 1990-95 that we see some upward and downward mobility with the former being higher. This is mainly driven by a number of medium populations size countries such as Pakistan and Iran moving one HDI band up and some less populated countries moving down. During the 1995-2002 period, there is more upward mobility mainly caused by the highly populated China and Bangladesh moving up one band. This resulted in a considerable change in the middle sections of distribution. The change in distribution for the entire period of 1975-2002 shows considerable mobility again in the middle part of distribution depicting a case of 'twin peaks' with the previously dominant lower middle band peak in the beginning of the period being replaced by an upper middle peak at the end of the period.

All this illustrates that there have been some signs of equalization in the distribution of HDI but a few populated countries mainly drive this. There are also signs of polarization particularly amongst the developing countries. While some countries, mainly in Asia and Latin America, have progressed considerably, SSA seems to have been caught in a deep trap of low human development with no signs of getting out of it. These countries are not moving in the direction of the MDG as expected and, if the current trends continue, by 2015 they would be worse off in some aspects such as poverty and nowhere near the goals for the remaining MDG. To ensure improvements in human development in poorer countries, who need this most, and a reduction in inequality far more effort under the MDG is needed. Given that poorer countries on their own lack the required resources for this purpose, as recognized by a number of 
reports, 20 far more rigorous efforts are required by international aid agencies and donor countries in order to change the current trends.

\section{References}

Barro, R.J. (1991). 'Economic Growth in a Cross Section of Countries', Quarterly Journal of Economics 106: 407-43.

Barro, R.J., and X. Sala-i-Martin (1992). 'Convergence', Journal of Political Economy 100: 223-51.

Barro, R.J., and X. Sala-i-Martin (1995). 'Economic Growth', McGraw Hill: New York.

Baumol, W.J. (1986). 'Productivity Growth, Convergence and Welfare: What the LongRun Data Show’, American Economic Review 76: 1072-85.

Baumol, W.J., and E.N. Wolff (1988). 'Productivity Growth, Convergence and Welfare: Reply’, American Economic Review 78: 1155-9.

Bourguignon, F., and C. Morrisson (2002). 'Inequality Among World Citizens: 18201992', American Economic Review 92(4): 727-44.

Chotikapanich, D., R. Valenzuela, and D.P. Rao (1997). 'Global and Regional Inequality in the Distribution of Income: Estimation with Limited and Incomplete Data', Empirical Economics 22: 533-46.

de la Fuente, A. (1997). 'The Empirics of Growth and Convergence: A Selective Review', Journal of Economic Dynamics \& Control 21: 23-73.

Dollar, D., and A. Kraay (2002a). 'Spreading the Wealth', Foreign Affairs 81(1): 12033.

Dollar, D., and A. Kraay (2002b). 'Inequality is No Myth', Foreign Affairs 81(4): 18283.

Dowrick, S., and M. Akmal (2005). 'Contradictory Trends in Global Income Inequality: A Tale of Two Biases', Review of Income and Wealth 51(2): 201-30.

Firebaugh, G. (1999). 'Empirics of World Income Inequality', The American Journal of Sociology 104(6): 1597-630.

Jones, C.I. (1997). 'On the Evolution of the World Income Distribution', Journal of Economic Perspectives 11(3): 19-36.

Hossain, A. (2000). Convergence of Per Capita Output Levels across Regions of Bangladesh, 1982-97', IMF Working paper WP/00/121, International Monetary Fund: Washington DC.

20 Such as WHO (2003); UNDP (2003). 
Korzeniewicz, R.P., and T. Moran (1997). 'World Economic Trends in the Distribution of Income, 1965-1992’, American Journal of Sociology 102: 1000-39.

Kosack, S. (2003). 'Effective Aid: How Democracy Allows Development Aid to Improve the Quality of Life', World Development 31(1): 1-22.

Mankiw, N.G., D. Romer, and D.N. Weil (1992). 'A Contribution to the Empirics of Economic Growth', Quarterly Journal of Economics 107(2): 407-37.

Martin, R., and P. Sunley (1998). 'Slow Convergence? The New Endogenous Growth Theory and Regional Development’, Economic Geography 74: 201-27.

McGillivray, M. (1991). 'The Human Development Index: Yet another Redundant Composite Development Indicator?', World Development 19(10): 1451-60.

McGillivray, M., and H. White (1993). 'Measuring Development? The UNDP's Human Development Index’, Journal of International Development 5(2): 183-92.

Milanovic, B. (1997). 'A Simple Way to Calculate the Gini Coefficient, and Some Implications', Economic Letters 56: 45-9.

Milanovic, B. (2002). 'True World Income Distribution, 1988 and 1993: First Calculation Based on Household Surveys Alone’, Economic Journal 112: 51-92.

Milanovic, B. (2003). 'The Two Faces of Globalization: Against Globalization as We Know It', World Development 31(4): 667-83.

Neumayer, E. (2001). 'The Human Development Index and Sustainability: A Constructive Proposal', Ecological Economics 39: 101-14.

Noorbakhsh, F. (1998). 'A Modified Human Development Index', World Development 26(3): 517-28.

Noorbakhsh, F. (1999). 'Standards of Living, Human Development Indices and Structural Adjustments in Developing Countries: An Empirical Investigation', Journal of International Development 11: 151-75.

Noorbakhsh, F. (2003). 'Human Development, Poverty and Disparities in the States of India', paper presented at the UNU-WIDER conference on Inequality, Poverty and Human Well-being, 30-31 May, Helsinki.

Pritchett, L. (1997). 'Divergence, Big Time', Journal of Economic Perspectives 11(3): 3-17.

Pyatt, G., C.N. Chen, and J. Fei (1980). 'The Distribution of Income by Factor Components', Quarterly Journal of Economics 95(3): 451-73.

Quah, D. (1993). 'Empirical Cross-Section Dynamics in Economic Growth', European Economic Review 37: 426-34. 
Quah, D.T. (1996a). 'Twin Peaks: Growth and Convergence in Models of Distribution Dynamics', Economic Journal 106: 1045-55.

Quah, D.T. (1996b). 'Empirics for Economic Growth and Convergence', European Economic Review 40: 1353-75.

Romer, P. (1986). 'Increasing Returns and Long-Run Growth', Journal of Political Economy 94: 1002-37.

Romer, P. (1990). 'Endogenous Technological Change', Journal of Political Economy 98: 71-102.

Sachs, J.D., and F. Larrain (1993). 'Macroeconomics in the Global Economy', Harvester Wheatsheat: New York.

Sahn, D.E., and D.C. Stifel (2003). 'Progress Towards the Millennium Development Goals in Africa', World Development 31(1): 23-52.

Sala-i-Martin, X. (1996). 'The Classical Approach to Convergence Analysis', Economic Journal 106: 1019-36.

Sala-i-Martin, X. (2002). 'The Disturbing 'Rise' of Global Income Inequality', NBER Working Papers 8904, National Bureau of Economic Research: Cambridge MA.

Schultz, T.P. (1998). 'Inequality in the Distribution of Personal Income in the World: How is it Changing and Why', Journal of Population Economics 11(3): 307-44.

Srinivasan, T.N. (1994). 'Human Development: A New Paradigm or Reinvention of the Wheel?', American Economic Review, Papers and Proceedings 84(2): 238-43.

UNDP (various). 'Human Development Report', Oxford University Press: New York and Oxford.

WHO (2002). The World Health Report 2002: Reducing Risks Promoting Healthy Life, WHO: Geneva.

WHO (2003). 'The World Health Report 2003: Shaping the Future’, WHO: Geneva.

Zind, R.G. (1991). 'Income convergence and divergence within and between LDC groups', World Development 19(6): 719-27. 